\title{
Effect of a family-centered model of HIV care on viral suppression and care retention among HIV-positive children in Swaziland
}

Project SOAR

Follow this and additional works at: https://knowledgecommons.popcouncil.org/departments_sbsr-hiv

Part of the Demography, Population, and Ecology Commons, Family, Life Course, and Society Commons, International Public Health Commons, Maternal and Child Health Commons, and the Medicine and Health Commons

How does access to this work benefit you? Let us know!

\section{Recommended Citation}

Project SOAR. 2017. "Effect of a family-centered model of HIV care on viral suppression and care retention among HIV-positive children in Swaziland," Activity brief. Washington, DC: Population Council. 


\section{Effect of a Family-centered Model of HIV Care on Viral Suppression and Care Retention Among HIV-positive Children in Swaziland}

Swaziland, along with many other countries in subSaharan Africa, has made substantial progress in preventing mother-to-child HIV transmission (MTCT). However, efforts to scale up antiretroviral treatment (ART) and achieve the UNAIDS "90-90-90" targets (90 percent diagnosed, 90 percent diagnosed on ART; 90 percent on ART virally suppressed) have been less robust for children compared with adults. This discrepancy reflects substantial gaps in essential services and numerous missed opportunities to engage children in care and provide effective ART.

Provision of ART has generally entailed separate adult and pediatric clinics because different areas of expertise and service organization have been required for the care of children and adults. Yet the provision of comprehensive pediatric HIV treatment, care, and support may more likely be achieved if the child is treated within the context of his/her family. In response, a new paradigm has emerged-familycentered care-that addresses the health needs of all family members, particularly the mother and child.

Research Partners: Swaziland Ministry of Health and Elizabeth Glaser Pediatric AIDS Foundation

Location: Hhohho region, Swaziland

Study Duration: 2016-2019

For more information, contact: Nobuhle Mthethwa, MOH National Pediatric HIV Advisor, bubu.mthethwa@gmail.com or Caspian Chouraya, EGPAF Technical Director, cchouraya@pedaids.org.

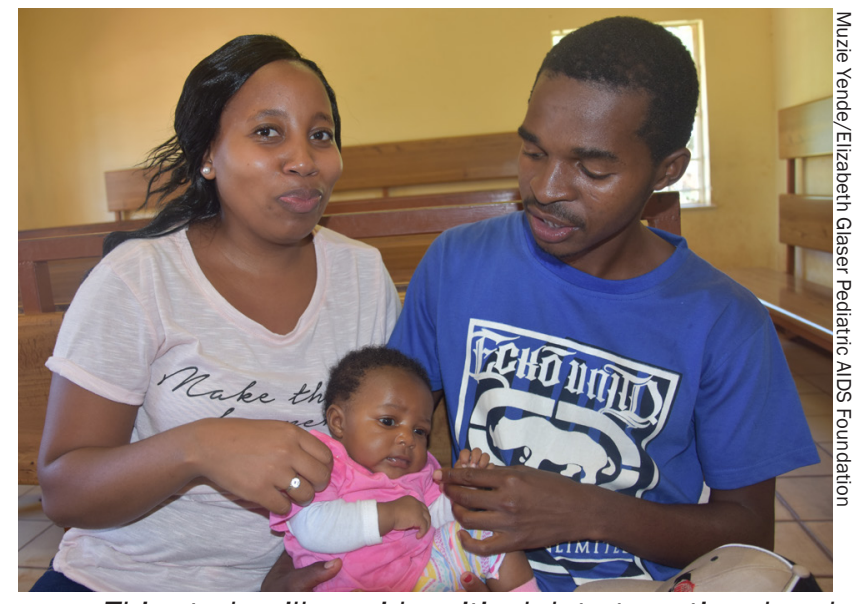

This study will provide critical data to national and global policymakers about the family-centered model of care's feasibility, acceptability, and effectiveness in busy, HIV service delivery facilities.

The Elizabeth Glaser Pediatric AIDS Foundation (EGPAF) is establishing a family-centered care (FAMCARE) service delivery program in selected health facilities in the Hhohho region of Swaziland. EGPAF has been supporting the Kingdom of Swaziland since 2003 to prevent MTCT and to provide care and treatment services to HIV-positive children and adults.

Project SOAR and the Swaziland Ministry of Health $(\mathrm{MOH})$ are leveraging this opportunity and a national roll-out of viral load monitoring to assess the implementation of the FAM-CARE program and its effect on viral suppression and retention in care among children living with HIV. This implementation science study is particularly important because it will provide critical data to national and global policymakers about the model's feasibility, acceptability, and effectiveness in busy, HIV service delivery facilities especially in achieving the last 90 of the 90-90-90 targets.
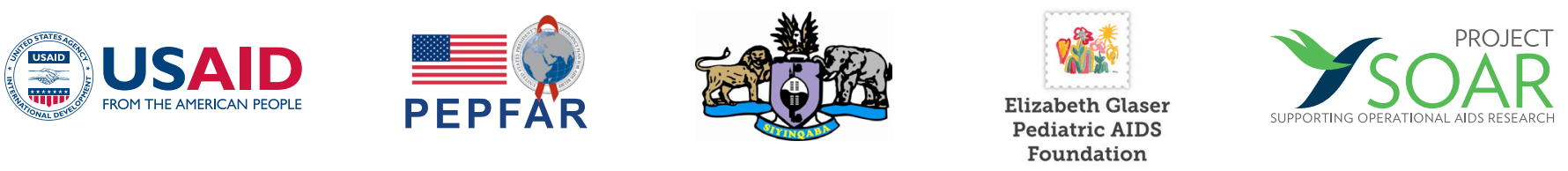


\section{What is FAM-CARE?}

The FAM-CARE approach is a way of caring for children and their families within health services that ensures care is planned around the whole family, not just an individual, and all family members are recognized as care recipients. The approach recognizes the vital role that families play in ensuring the health and well-being of infants, children, adolescents, and family members of all ages.

In the FAM-CARE model, health care providers see all HIV-positive family members on the same day. This may decrease their workload since providers will not have to see individual family members on different days; this may also benefit the family by decreasing the amount of times they are required to come to the facility for clinic visits or to pick up ART. Additionally, the model ensures counselling and education are provided to the family as a unit, which may foster collective support for family members.

\section{Our Research}

This research is a two-arm, prospective cohort study that will enroll more than 650 HIV-positive children-including over 440 HIV-positive children receiving $A R T$ who are from a unique family; half of the children will be in the intervention arm and half will be in the control arm. These children and their families will be seeking care at eight health care facilities in Hhohho region (four randomized to offer the FAM-CARE pilot program and the other four to continue offering the standard of care with separate pediatric and adult HIV clinics). The children in the study, ages 0-14, will be followed for 18 months.

Over the 18-month period the research team will collect data on the HIV-positive children quarterly from their medical records and from interviews with caregivers. They will also collect qualitative data via interviews with health care providers and caregivers from the intervention facilities at the end of the 18-month follow-up period to assess the feasibility and acceptability of the program.

\section{Research Utilization}

The study team has developed a strategy to promote research utilization from the beginning. It involves gaining input from stakeholders on the research concept, forming a research advisory committee (RAC), and involving the RAC and other stakeholders in data interpretation and in drafting an advocacy and use plan. Key stakeholders being engaged include the Swaziland National AIDS Programme (SNAP) and its' Pediatric HIV Care and Treatment Technical Working Group, Hhohho Regional Health Management Team, Swaziland $\mathrm{MOH}$, and the United States Agency for International Development.

\section{What Will We Learn?}

The effect of the FAM-CARE program on:

- Rates of viral suppression and HIV RNA level $>1,000$ copies/mL in HIV-positive children on ART, and factors associated with these endpoints.

- Missed visits, time out of care, and loss to follow-up of HIV-positive children (pre-ART and on ART), compared to the current standard of care program, and the association of these outcomes with viral suppression.

- ART initiation among HIV-positive children not on ART at study entry.

The feasibility and acceptability of the FAMCARE program to caregivers and health care providers.
Project SOAR is a five-year (September 2014-September 2019) cooperative agreement funded by the President's Emergency Plan for AIDS Relief and the United States Agency for International Development (USAID)-Agreement No. AID-OAA-A-14-00060. Project SOAR is able to accept funding from all USAID accounts.

The Population Council leads the Project SOAR consortium in collaboration with Avenir Health, Elizabeth Glaser Pediatric AIDS Foundation, the Johns Hopkins University, Palladium, and The University of North Carolina at Chapel Hill.
Project SOAR/Population Council 4301 Connecticut Avenue, NW, Suite 280 Washington, DC 20008 Tel: +1202 2379400 e-mail: ProjectSOAR@popcouncil.org popcouncil.org/ProjectSOAR

(c)Population Council, March 2017 